\title{
Application and Development Prospects of Network Technology in Physical Education of Universities
}

\author{
Liqun Su \\ ${ }^{1}$ Zhuhai College Of Jilin University, Zhuhai, Guangdong, China \\ a195187123@qq.com
}

Keywords: Network Technology, Universities, Physical Education, Teaching Management.

\begin{abstract}
In recent years, with the degree of information technology continues to improve, the teaching mode gradually develop in the direction of the network at the same time, this new mode of teaching is still not mature, but also exposed some problems to solve. In this paper, the characteristics of network teaching mode, the system inquiry teaching mode network management problems in the background, and in relation to patterns suggest ways to better use.
\end{abstract}

\section{Introduction}

In the social market economy, sports and international exchanges become more frequent, democratic and scientific decision-making continues to improve the degree of sport, which is bound to the development of sport management put forward new demands [1]. Currently, the urgent need to strengthen research related to sports management system and operational mechanism, in order to improve the overall level of China's sports manager, and the establishment of a sound macro-control mechanism for sports management, establish and improve related supervision and feedback mechanism. At the same time, the development of sports management will also be some radical changes; first, pay attention to the theoretical study by researcher's importance into practice in order to achieve a combination of theory and practice [2]. Second, the research study conducted by the administrative organization of emphasis on research into the importance of non administrative organization, such as the professional clubs, sports associations, sports associations and other organizations [1,2]. Third, pay attention to the study of sports management into the social importance of sports management school sports management studies. Fourth, the emphasis on hardware research study into the soft environment of great importance. Fifth, the research emphases on research into non-profit organizations profit organizations are played more attention. Sixth, sports management as a breakthrough, and gradually make sports management into the whole social environment managed. Seventh, in the management method to study the combination of qualitative and quantitative than qualitative research are played more attention, and introduced the theory of system science to make rational decisions [2].

In recent years, with the rapid development and continuous improvement of the socialist market economy, sports system, sports practice management field has been expanded, the demand for sports management professionals more urgent, suggesting Sports Management is a powerful vitality and has broad prospects for development disciplines [3]. Meanwhile, with the continuous deepening of the reform of sports, computer and network technology in all walks of life have been widely used, but it is also increasingly play an important supporting role in sports training. Especially in scientific sports training, systematic, standardized effect is more obvious, not only to improve training efficiency and athletic performance, but also to avoid some sports injuries. Making physical training had very subjective exercise, can objectively training, have to say is a leap in the history of sports.

\section{The New Model of Universities Physical Teaching Management Network Technology Problems}

Teaching management practices affect the Network Technology is obvious, but because, as a new class of things, its development path has not been smooth, still produce a large number of issues, the following were detailed to clarify: 
Host-guest relationship management fuzzy Physical Teaching. Host-guest relationship management teaching university network technology is definitely not under the old, simple correlation system, but with rich colors era. At the same time, produce and play the role of the social role of virtual fields are gradually emerging, these intricate web of factors that makes today's university teaching management and social conditions in host-guest relationship with the nature of the above changes [4]. However, in reality, the teaching management in the primary object relations remains uncertain; the issue cannot be a good grasp of the relationship between the new network technologies arising under the new situation.

Students will be treated as a simple form of entertainment of physical teaching, and has not be applied effectively. China's higher education because there are more spare time, these students generally use the network to play games, watch movies, chat or online, everyday school life, we relax the Internet as a means of entertainment [4]. However, the introduction of the network teaching management, students will feel the use of the network just to make teaching more interesting and full of vitality and borrowed carrier, in the ideological level did the network as a new model of teaching, which is not conducive to the network improve teaching management in the context of.

Students use the network approach is not appropriate to apply the physical teaching brought trouble. Network-based teaching can break through the traditional limitations of time and space, so that anyone at any time can get a variety of knowledge, with a high degree of flexibility, learners can freely dispose of learning time, very easy and fast. Network resources are very large, with the help of technical means of a combination of multi-media, college students will get a variety of teaching resources, shorten the distance of time and space, to improve the effectiveness of learning. However, in reality, very few college students to be considered as a means of learning, but purely personal entertainment, even when teachers in teaching, students are not active and effective cooperation [5]. Especially teaching students to use computers arrange independent study, some students "could not" play games or surfing the Internet, which is changing the network environment of teaching management model is very unfavorable.

\section{The new Application Methods Mode of Universities Physical Teaching Management based on Network Technology}

Strengthen the two teaching management model.Although the two-stage management colleges already begun preliminary, but a lot of work still has to continue to do so [6]. At present, the management system of this level are not enough to guide the tertiary institutions teaching management still has many loopholes and technical blind spots, urgently clear responsibilities of all parties, to enhance the sense of responsibility. Universities should gradually teaching in the department-level management to the first line will strengthen the coordination between the Departments, the ability to communicate, give full play a key role in the education system reform, teaching and management work. Joint response mechanism must be established between the university system sound, clear their objectives [6], bold attempt to explore management methods, giving more rights system, so that in the system-level performance evaluation of teaching, advanced educator grant award, the new personnel training and managed network configuration based curriculum and other aspects under the authority, to further develop the effectiveness of the department of standardized performance of their duties.

Raising awareness, changing concepts, improve teaching mode. Teaching mode network environment different from the past tradition, the old way of teaching, the difference between the performances of the network teaching mode is more certainly the dominant position of the students, which is self-learning ability of students. Students are already adult's age, and after ten years of classroom life, one of the important gains obtained is to develop the individual's ability to learn. University itself is much stressed students to explore their own, the ability to analyze and solve practical problems $[5,7]$. Based on this, both teachers and students should first realize the importance and value of self-learning. Secondly, under the network environment is most conducive and most in line with the conditions of self-study, which must be determined so that teachers working to change 
the past, "many" indoctrination, cramming kind of teaching mode, build a student, teacher only plays the role of organizer and guide teaching multidimensional interactive teaching mode [7]. This will also help students in the teaching process of the initiative, to stimulate their divergent thinking, creative thinking and associative thinking, personal ingenuity applied to the above teaching.

Management team of high qualified physical education building. Development of university teaching management team is very uneven, especially lower the overall quality of the grass-roots management staff, the individual does not actually worked in college, or personal computer had little contact, not even basic network operation, teaching lack of rational understanding. Get to the bottom of its cause, is due to the role of senior management staff teaching lower-level managers and functional understanding of vague, and thus do not attract enough attention [8]. Basic Teaching communication and contact managers as a bridge between the teaching of each system and the Office of Academic Affairs, has an essential influence on the management of the entire work of teaching. So, in order to effectively promote college teaching management smoothly toward modernization and rationalization of rail network, improve network quality and the overall quality of teaching staff management becomes imperative.

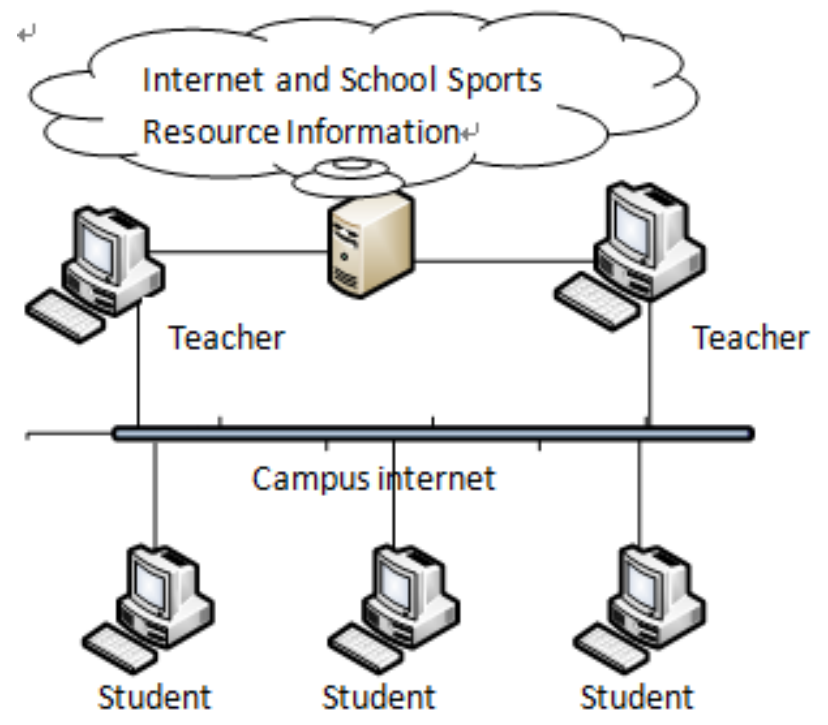

Fig.1 Network physical teaching mode

Construct a reasonable teaching management team, the first task is to strengthen the teaching of the former managers of induction training, will closely examine its entry, only the successful completion of the assessment, in order to be hired by universities [9]. Secondly, universities need to establish a sound long-term management of the training system, the training of educational administrators included in the target range, be systematic and scientific training on a regular basis, by organizing seminars and exchange of information technology IT applications basics contests and other activities to promote the teaching management staff to update and improve it in the minds of industry knowledge and understanding of laws and regulations, information technology, compliance with national norms and ethics network, and understand it the forefront of industry, to stimulate the use of information management skills teaching initiative and creativity, so teaching managers to fully recognize the importance of information skills while gradually learn to use online teaching resources [8,9]. Fig. 1 is a physical education network schematic. Through the campus network of students and teachers machine machine can be connected together, and then the teacher machine unified custom web content downloaded to the server for students to access.

\section{Summary and Prospects}

Network for the modern physical education has injected new vitality, but also brings new opportunities and challenges. Traditional physical education, and only continue to absorb fresh knowledge from outside information, to get progress and development. As the current teaching sports 
colleges researchers should recognize forms, timely change their ideas, update their knowledge, take full advantage of this human valuable wealth of knowledge, and strive to change the current presence in Physical Education College in the passive, backwardness, only in this way can continue to develop college sports, sports talent to cultivate a more responsive to the community. I believe that in the near future, when all kinds of modern educational technology has been widely used in physical education, our sport will radiate vigor and vitality.

\section{References}

[1] Q.L. Hu, Network technology application and development prospects, Higher Education Management in Hubei University of Economics (Humanities and Social Sciences), vol.3, pp. 215-216, 2012. (In Chinese)

[2] L.L. Jin, On the Necessity of assisted teaching university network management platform, Success (Education), vol.12, pp. 212-215, 2009. (In Chinese)

[3] Y. Wu, Senate NMS in College Teaching Management, Yangtze University (Natural Science Edition) Sci, vol.1, pp. 243-244,2010. (In Chinese)

[4] Q.Y. Zhang, Intelligent network-based teaching management in a new model, Jiamusi Education Institute, vol.4, pp.131-133,2011. (In Chinese)

[5] F.H. Gong, Sh.X. Fan, University network teaching platform based Teaching Management Perspective, China. university teaching, vol.9, pp. 57-59,2010. (In Chinese)

[6] J.H. Zheng, Y.Zh. Xiong, Design and Implementation of Network Teaching Management System , Shanghai China, pp. 495-498,2010. (In Chinese)

[7] Q.M. Liu, X. Peng and Q. Liu, Reflections teaching intelligent building management network ,Technology \& Development, vol.10, pp.185-187, 2010. (In Chinese)

[8] W. Ding and Zh.Y. Yu, Research of university teaching management philosophy and quality monitoring system, Shanxi Social Science Journal, vol.6, pp.95-97, 2011. (In Chinese)

[9] X.W. Zhong, Undergraduate of teaching management thinking and countermeasures, Architectural Education, vol.1, pp. 167-171, 2011. (In Chinese) 